\title{
FAILURE MODE SHIFTS DURING CONSTANT AMPLITUDE FATIGUE LOADING OF SANDWICH BEAMS
}

\author{
Dan Zenkert and Magnus Burman \\ Department of Aeronautical and Vehicle Engineering \\ Kungliga Tekniska Högskolan, SE-10044 Stockholm, Sweden \\ danz@kth.se, $\underline{\text { mburman@kth.se }}$
}

Zenkert D. and Burman M., "Failure Mode Shifts during Constant Amplitude Loading of GFRP/foam core Sandwich Beams", International Journal of Fatigue, Vol 33, 2011, pp 217 222, http://dx.doi.org/10.1016/j.ijfatigue.2010.08.005 


\title{
FAILURE MODE SHIFTS DURING CONSTANT AMPLITUDE FATIGUE LOADING OF SANDWICH BEAMS
}

\author{
Dan Zenkert and Magnus Burman \\ Department of Aeronautical and Vehicle Engineering \\ Kungliga Tekniska Högskolan, SE-10044 Stockholm, Sweden \\ danz@kth.se, $\underline{\text { mburman@kth.se }}$
}

\begin{abstract}
This paper presents fatigue results for sandwich beams that exhibit a transition in failure mode, from core shear failure to face laminate tensile failure, as function of load amplitude only. The basis of this are fatigue tests of foam cores in shear and tensile tests on composite laminates. These results show that the slopes of the stress-life (S-N) relation are different for the core and laminates. By using the obtained stress-life relations, a simple design scheme is given for sandwich beams which are anticipated to have a transition of failure mode for a particular load level. Two designs are manufactured and tested in fatigue under constant amplitude loading. The results clearly show the aim of investigation with transitions in failure modes giving a structural stress-life diagram a bi-linear shape. For high load and small number of cycles to failure, the beams fail by face tensile fracture while for lower loads, and large number of cycles to failure the beams fail by core shear.
\end{abstract}

Keywords: Fatigue life, sandwich beam, composite, foam core, failure modes

\section{INTRODUCTION}

Sandwich structures offer many potential advantages such as high relative stiffness and strength to weight ratios which is utilised in many weight critical applications. A challenge in the design of sandwich structures is to accurately predict the many potential modes of failure that may occur. Two of the most obvious competing failure modes in the design of simple sandwich beams and panels are face tension/compression fracture and core shear failure. For static loading conditions, one can actually choose which failure mode should be active by 
appropriate design of the beam or panel, simply by ensuring that the load required for one failure mode is sufficiently higher than for the other(s). In shipbuilding for example, this is commonly utilised. Underwater hull panels in composite sandwich ships are normally designed so that core shear failure appears before fracture of the laminates. In this way, the panel can fracture, but still be watertight. In fatigue loading, the design towards particular failure modes is slightly more complex, and this is what this paper deals with.

Some early work on fatigue of foam core sandwich structures were performed by Burman et al [1-2], Shenoi et al [3] ], Kanny et al [4-5] and Kulkarni et al [6]. They all used beam bending tests, designed for core shear failure, to find the fatigue response of foam cores subjected to shear loading. The testing resulted in stress-life relations for various polymeric foam cores. In [7] the authors used an initial flaw approach model through which the crack propagation data could be transformed to stress-life curves. The model gave excellent agreement with measured crack propagation data and tension-tension fatigue testing results for two closed cell polymer foams, the same two foams used herein. In a subsequent investigation, the fatigue behaviour of Rohacell WF-foams in tension, compression and shear was investigated [8]. It was found that the slope of the stress-life curve was different for different load cases and relative densities.

Since sandwich structures also can fail by face sheet failure, the fatigue behaviour of the face sheet laminates also needs to be established. There exists quite a lot of information about fatigue of composite laminates in the literature, albeit more limited concerning laminates made from so called non-crimp fabrics (NCF's). Kahn and Mouritz [9] compared stitched and non-stiched composite laminates and concluded that the stitching has a negative influence on the tensile fatigue performance. The same conclusions were drawn from a later investigation [10]. Gagel et al [11,12] studied the formation of cracks and stiffness degradation of glassfibre NCF-laminates subjected to tensile fatigue loading concluding that some of the microcrack formation processes are the same as under quasi-static loading. They also developed a model for the mechanical degradation under fatigue loading. Vallons et al $[13,14]$ studied the formation of micro-cracks in carbon fibre NCF-laminated under fatigue loading. They used Acustic Emission (AE) techniques and X-ray imaging to study micro-cracks and experimental 
measured the stiffness degradation. An interesting finding was that for a $[+45 /-45]_{\mathrm{s}}-1$ aminate the fatigue endurance limit (the strain under which there is an apparent infinite fatigue life) can be found from the linear part of the stress-strain relation in a simple tensile test. For $[0 / 90]_{\mathrm{s}}$ it seems that the fatigue endurance limit is well above the stress level for damage initiation under static loads. Aono et al [15] performed tension-tension and tensioncompression fatigue experiments on [+45/-45] NCF-laminates. There are two interesting observations from this work; testing at $R=-1$ gives higher fatigue life than at $R=0.1$, and the failure modes are different. In a subsequent paper, Aono et al [16] also studied glass fibre NCF-laminates and used replica methods to monitor fatigue damage progression under tensile fatigue loading. They found that damage was first initiated near the stitches, in resin rich regions. An industrial sector where fatigue of composite laminates is very important is in wind power. Many wind turbine blades are made from glass NCF's and fatigue is one of the main design constraints [17]. There is a very comprehensive investigation of fatigue of laminates for wind turbine applications made by Nijssen [18]. There are some constant amplitude data in there, though most of the work focuses on spectrum fatigue loading.

This paper will not deal with a detailed description of the fatigue damage progression but will study fatigue as a design problem. It is rationalised that even if a sandwich structure is designed to fail with a given failure mode (e.g. core shear failure) under quasi-static loads, the failure mode can shift (to e.g. face sheet failure) under fatigue loading. The foundation for this hypothesis is that the slope of the stress-life relations for different failure modes can be different. Thus, the same sandwich structure, with the same material combination, under the same loading condition, but with different loading amplitude, can have different failure modes in fatigue.

\section{MATERIALS}

Two high performance rigid polymer foams with closed cell structure were used in this study; Divinycell H-grade and Rohacell WF-grade. Divinycell is a cross-linked rigid cellular PVC foam and it is produced in a variety of densities where mechanical properties (higher strength and moduli) increase with density. The quality used here was H100, with a nominal density of 
$100 \mathrm{~kg} / \mathrm{m}^{3}$. Any details on this material can be found in [19]. The other core material used in this study is Rohacell, a PMI foam with predominantly closed cells but is more brittle than the PVC foam. The quality used herein was WF51, where WF is the particular grade of Rohacell and the number corresponds to the nominal density in $\mathrm{kg} / \mathrm{m}^{3}$. Details on this material can be found in [20]. The reason for choosing these two materials is that one exhibits a fairly brittle behaviour (Rohacell) in the context of foams and the other (Divinycell) has a more ductile behaviour (higher strain to failure, a more pronounced plastic regime). They further exhibit different behaviour in fatigue. Both materials are close to being isotropic, with only small variations in moduli and strengths in the in-plane and out-of-plane directions.

The laminates used herein were made from glass-fibre NCF fabrics of the type DBLT-850E10 [21]. This is a quadriaxial non-crimp fabric (NCF) with approximately equal amount of fibres, approximately $200 \mathrm{~g} / \mathrm{m}^{2}$, in four main directions in the sequence [0/45/90/-45]. The laminates were manufactured using a vacuum infusion process (VARTM) with Reichhold DION 9500 Vinylester. A single layer of DBLT-850 builds approximately $0.75 \mathrm{~mm}$ after infusion. Typical material data for the cores and the laminates are given in Table 1. The yield stress for the cores is defined as the stress at $0.5 \%$ offset strain.

\begin{tabular}{|l|c|c|c|}
\hline & WF51 & H100 & Laminate \\
\hline$E[\mathrm{MPa}]$ & 75 & 126 & 15,000 \\
\hline$G[\mathrm{MPa}]$ & 27 & 40 & - \\
\hline$\sigma_{1}[\mathrm{MPa}]$ & 1.6 & 3.3 & 310 \\
\hline$\tau_{\text {yield }}[\mathrm{MPa}]$ & 0.66 & 1.13 & - \\
\hline$\tau_{\text {failure }}[\mathrm{MPa}]$ & 0.77 & 1.21 & \\
\hline
\end{tabular}

Table 1 Basic material data for the material used.

\section{SHEAR FATIGUE TESTING OF CORE MATERIALS}

A four point bending rig which enables fatigue loading with both positive and negative loads was used in this investigation, as depicted schematically in Fig.1a. This design allows the supports to rotate around the neutral axis of the beam in order to minimise the stress concentrations near the load introductions. Furthermore the supports are movable in the beam length direction to enable varying settings of $L_{1}$ and $L_{2}$ (see Fig.1a). The supports are also 
covered with rubber pads in order to smooth out the load transfer. The outer load arms are allowed to move horizontally thus preventing any membrane forces to occur.

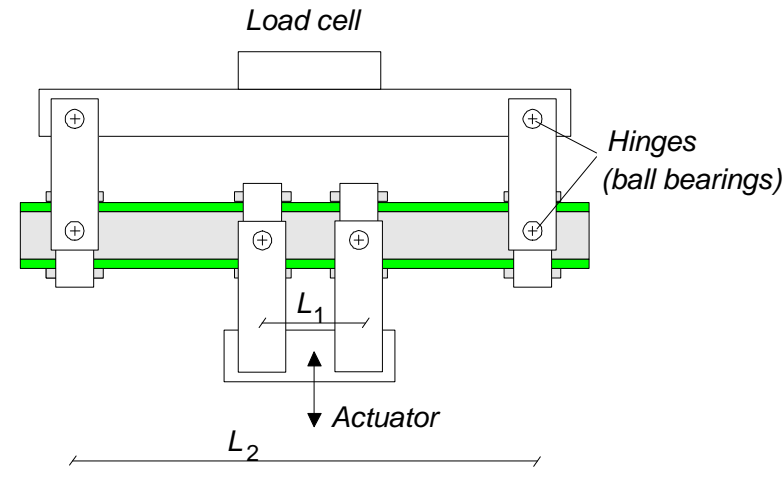

(a)

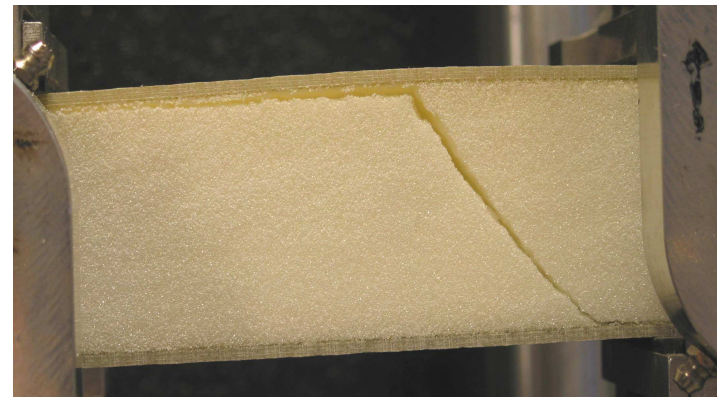

(b)

Figure 1 (a) Schematic set-up for fatigue testing of foams using four-point bending test. (b) Photograph of a fractured WF51 test specimen in the test rig.

This type of specimen has been used extensively (see e.g. [1]), to perform fatigue tests of foams. The basis is that in the region between the outer and inner supports, the transverse load, and thus the core shear stress, is constant. By design, the specimens will exhibit core shear failure, rather than face sheet failure, e.g. by making the face sheet thick enough to ensure that the face sheet stresses are low enough. Another rationale is that the fatigue test of the core is actually performed in a manner very similar to the actual use of the structure.

All specimens were $500 \mathrm{~mm}$ long, a width equal to the thickness, and tested using the set-up, $L_{1}=80 \mathrm{~mm}$ and $L_{2}=440 \mathrm{~mm}$. A $50 \mathrm{~mm}$ thick core was used with approximately $4 \mathrm{~mm}$ thick faces. The testing was performed at $R=0.1$, room temperature and at a testing frequency of 2 $\mathrm{Hz}$ with a sinusoidal loading.

The shear failure in fatigue of the WF51 specimens is similar to that under quasi-static loading with a sudden shear crack appearing, Fig.1b. For the H100-specimens, the core appears to collapse in a horizontal band, but the beam does not really suddenly fracture.

The results from this testing is shown in Fig.2a as standard stress-life relations plotted in double logarithmic scale. The dashed lines in Fig.2 represent the yield stress in shear for the foam. This is defined by the $0.5 \%$ offset stress [8]. There are a few things to notice in Fig.2a. Above the yield stress, the fatigue life has very large scatter, which is clearly seen for the H100 material. Therefore, high-cycle fatigue is defined for stress levels below the yield point. 
The number of cycles to failure at yield is different for the two materials; approximately $10^{2}$ for WF51 and $10^{4}$ for H100. Another important thing is that the slope of the fatigue life relation in the high-cycle fatigue regime is different. The stress-life data can be adapted to a Basquin's law type relation that reads

$$
\Delta \sigma=B(N)^{-1 / \beta}
$$

where $\Delta \sigma$ is the stress range, $N$ the number of cycles to failure, $B$ a fitting constant and $-1 / \beta$ the slope of the relation. The fitted data in Fig.2 gives the slope $\beta$ to approximately 20 for WF51 and 12 for H100.

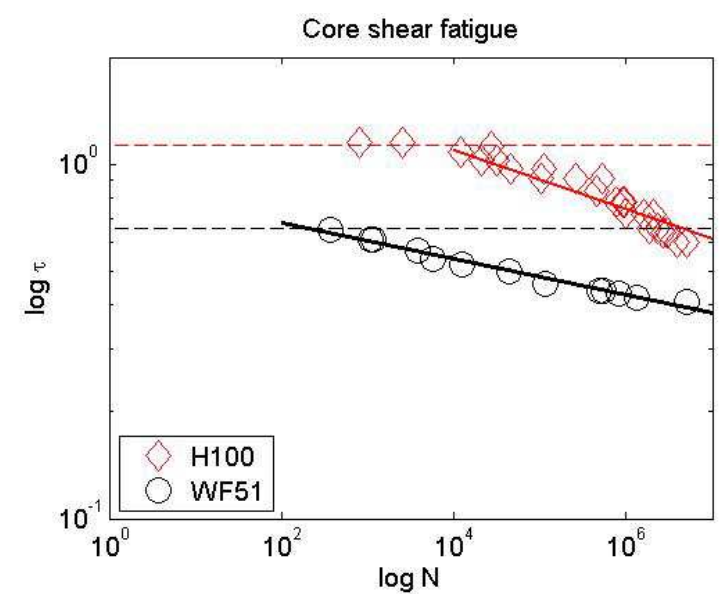

(a)

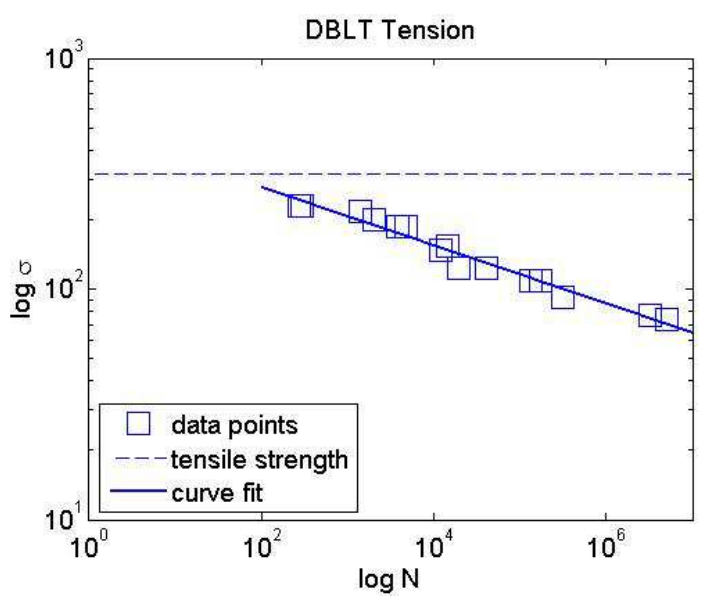

(b)

Figure 2 (a) Shear fatigue data for $\mathrm{H} 100$ and WF51 core, and (b) tensile fatigue data for the DBLT laminate in tension

\section{TENSILE FATIGUE TESTING OF LAMINATES}

The tensile fatigue testing of the laminates were performed on laminates consisting of 2 layers of DBLT-850, giving a lay-up sequence of $[0 / 45 / 90 /-45]_{\mathrm{s}}$ with a total thickness of approximately $1.5 \mathrm{~mm}$. Rectangular, tabbed specimens were used, as shown in Fig.3(a-b). The width of the specimens was $25 \mathrm{~mm}$ and the gauge length was $100 \mathrm{~mm}$. The fatigue testing was performed in a standard servo-hydraulic testing machine with a $2 \mathrm{~Hz}$ sinusoidal loading, at room temperature and with a loading ratio $R=0.1$.

The specimens failed abruptly with no or very little visual signs of damage prior to complete rupture. A ruptured specimen is shown in Fig.3c. 


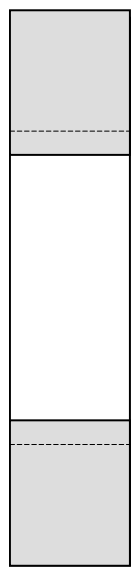

(a)

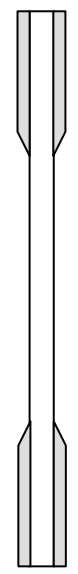

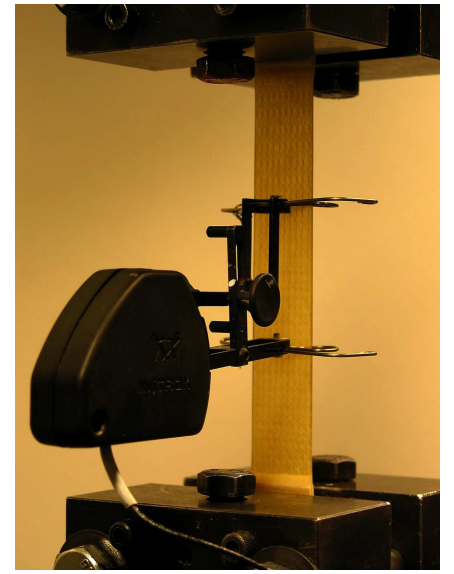

(b)

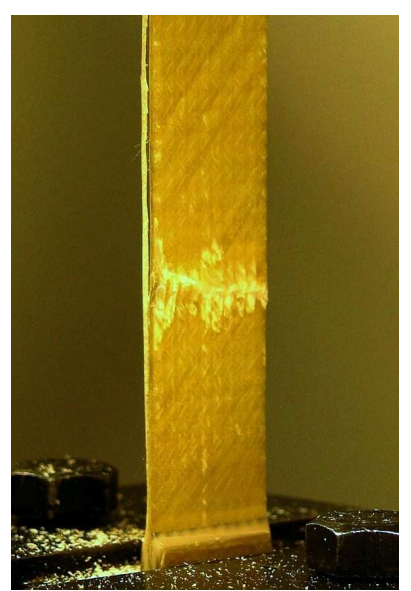

(c)

Figure 3 (a) Schematic set-up for fatigue testing of laminates. (c) Photograph of experimental set-up. (b) Photograph of a fractured laminate in the test rig.

The results of the laminate testing is summarised in Fig.2b by means of a stress-life diagram in double logarithmic scale. The slope, $\beta$, according to eq.(1) of this stress-life curve is approximately equal to 8 (7.8 using curve fit). This is similar to what was reported in [17] where a slope of 8.7 can be deduced for tension fatigue at $R=0.1$. In the work by Nijssen [18] a slope $\beta=9.9$ is reported. In other investigations, e.g. $[14,16]$ the slope deduced from stresslife relations differs a lot, but appears to be around or above 10 in most cases.

\section{DESIGN OF SANDWICH BEAMS}

We now wish to design a sandwich beam that exhibits two competing failure modes; core shear failure and face sheet tensile fracture. Starting from the four-point bending set-up depicted in Fig.4(a), one can formulate the following;

Define the load going into the beam at each support as $P$. The transverse force between the inner and outer supports, $T$ is then equal to $P$. Between the inner supports the transverse force is equal to zero. The bending moment is zero at the outer supports (since they are hinged), linearly increasing towards the inner supports. Between the inner supports, the bending moment is constant and equal to $P\left(L_{2}-L_{1}\right) / 2$. By using classical sandwich theory, with the assumption of constant core shear stress, one can write the stresses in the core and the face sheets as [22] 


$$
\sigma_{1}=\frac{M}{t_{1} d}=\frac{P\left(L_{2}-L_{1}\right)}{2 t_{1} d}, \sigma_{2}=\frac{M}{t_{2} d}=\frac{P\left(L_{2}-L_{1}\right)}{2 t_{2} d} \text { and } \tau_{c}=\frac{P}{d}
$$

where $t_{1}$ and $t_{2}$ are the thicknesses related to the upper and lower face and $t_{c}$ to the core. The distance between the centreoids of the laminates is $d=t_{c}+\left(t_{1}+t_{2}\right) / 2$, see Fig4(b). If we apply a fatigue load with the ratio $R>0$ so that the lower face sheet is subjected to tension and the upper face sheet to compression, then the tensile stress in the lower face sheet will always be higher than the compressive stress in the upper face sheet if we make a sandwich beam with $t_{1}$ $>t_{2}$. By doing this, we can ensure that face failure will occur in the bottom laminate, subjected to tension. This is a simplification done since we lack data for the fatigue properties of the laminate in compression.

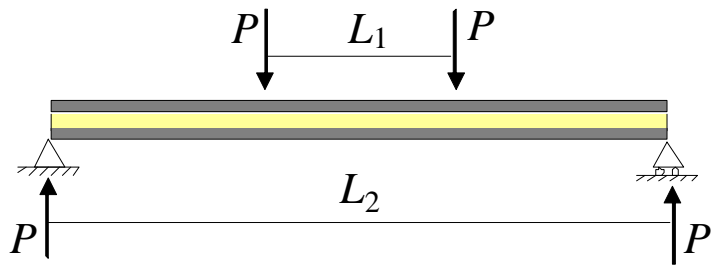

(a)

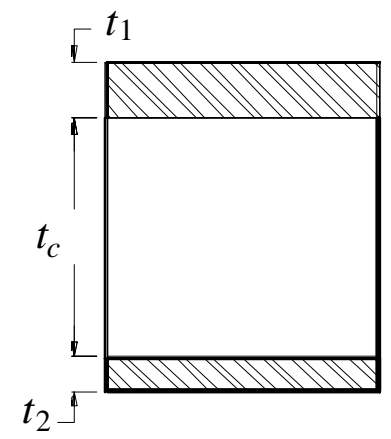

(b)

Figure 4 (a) Schematic of four-point bending set-up and (b) definition of sandwich beam cross-section

By using eqs.(2) one can design a sandwich beam through the use of the parameters $t_{1}, t_{2}$, and $t_{c}$, together with the structural geometry, in this case defined simply by $L_{1}$ and $L_{2}$, towards a specific failure more (face tensile fracture or core shear failure). Take eqs.(2) and rewrite into

$$
P=\frac{\sigma_{2}(N) t_{2} d}{L_{2}-L_{1}} \text { and } P=\tau_{c}(N) d
$$

where the stress is taken as function of fatigue loading cycles to failure according to Fig.2a and $2 \mathrm{~b}$, for the core and face sheet, respectively. In doing so, we get a fatigue life relation for the sandwich beam, i.e. $P$ as function of number of cycles to failure, with two stress-life curves, one for the face sheet and one for the core. These two relations can be altered through appropriate design (choosing $t_{1}, t_{2}, t_{c}, L_{1}$ and $L_{2}$ ). The aim now is to design sandwich beams 
for which the two stress-life relations cross each other for some value of the load, implying that the beam will shift failure mode depending on the amplitude of the fatigue load.

\section{TESTING OF SANDWICH BEAMS}

Two sets of sandwich beams were designed in order to attempt to promote failure mode shift in fatigue loading. They are defined in Table 2.

\begin{tabular}{|c|c|c|}
\hline & Design 1 - H100 core & Design 2 - WF51 core \\
\hline Upper face sheet & 2 layers DBLT- symmetric & 2 layers DBLT- symmetric \\
\hline Lower face sheet & 4 layers DBLT- symmetric & 4 layers DBLT- symmetric \\
\hline Core & H100 & WF51 \\
\hline tc $[\mathrm{mm}]$ & 50 & 50 \\
\hline t1 $[\mathrm{mm}]$ & 3.0 & 3.0 \\
\hline t2 $[\mathrm{mm}]$ & 1.5 & 1.5 \\
\hline L1 $[\mathrm{mm}]$ & 80 & 175 \\
\hline L2 $[\mathrm{mm}]$ & 500 & 1000 \\
\hline
\end{tabular}

Table 2 Definition of sandwich beam designs used in testing

The laminate subjected to tensile stress in the beam tests were in both cases made for a lay-up sequence of $[0 / 45 / 90 /-45]_{\mathrm{s}}$ and the laminate subjected to compression was twice as thick with a lay-up sequence of $\left[(0 / 45 / 90 /-45)_{2}\right]_{\mathrm{s}}$. The testing was performed using a sinusoidally varying load at $R=0.1$ and at room temperature. A testing frequency of $2 \mathrm{~Hz}$ was used for the $\mathrm{H} 100$ beams, but only $1 \mathrm{~Hz}$ for the WF51. The reason for the lower frequency in that case was simply because the beams were much longer, therefore with more deflection.

The collected results for the H100 and WF51 beams are shown in Fig.5. The dashed horizontal lines represent the load level for assumed quasi-static failure and the solid lines tensile face sheet fracture and core yield, respectively. For the H100 beams, Fig.5a, the expected failure load for tensile laminate fracture is $109 \mathrm{~N} / \mathrm{mm}$ width, and for core failure 59 $\mathrm{N} / \mathrm{mm}$ width. This beam is thus statically designed for core shear failure. The solid lines represent fatigue data for the materials through the use of eq.(3) and the test results of the cores and laminates. As seen, the design in this case indicates that the failure mode should shift from core shear to face failure when the load is decreased. This happens at a load level when the expected life is slightly less than $10^{4}$ load cycles. The experimental results are 
almost perfect agreement with the prediction in this case. Above $10^{4}$ load cycles, the failure mode is tensile face failure and below it is core shear.

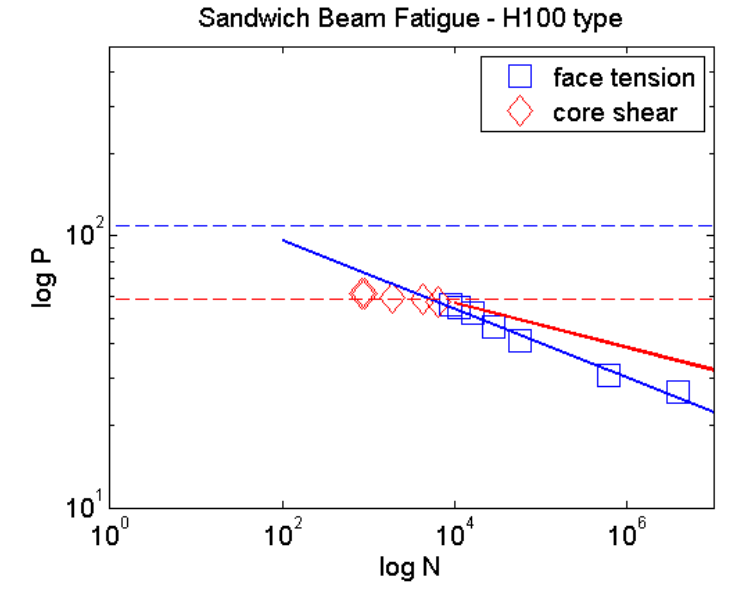

(a)

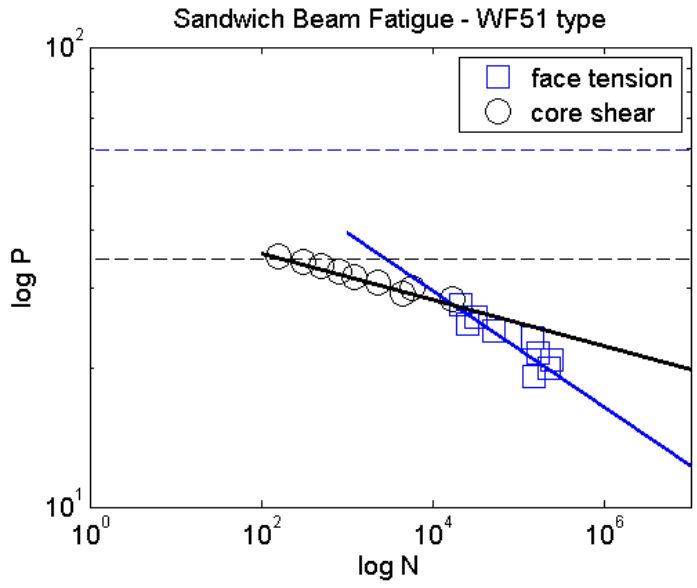

(b)

Figure 5 Test results from four-point bending fatigue testing of (a) $\mathrm{H} 100$ beam design and (b) WF51 beam design. Square markers indicate face tensile fatigue failure and diamond and circular markers indicate core shear fatigue failure.

The collected results for the WF51 beams are shown in Fig.5b. The expected failure load for tensile laminate fracture is $60 \mathrm{~N} / \mathrm{mm}$ width, and for core failure $34.5 \mathrm{~N} / \mathrm{mm}$ width. As for the H100 beam types, there is a predicted failure mode shift from core shear to face failure when the load is decreased. This should happen at a load level when the expected life is slightly above $10^{4}$ load cycles. As seen in Fig.5(b) there is again an almost prefect match between the test results and the prediction.

The failure modes are shown in Fig.6. The core shear failure of the H100 beams is a little hard to elude to. The H100 is rather ductile and does not really fail abruptly. Instead, a shear band is created in which the core rather collapses. When this happens the entire beam collapses. To highlight this, horizontal and vertical lines were drawn on the surface of the core. Details on the failure evolution are described in [1]. The face tensile failure appears abruptly without any prior visual signs of degradation. 


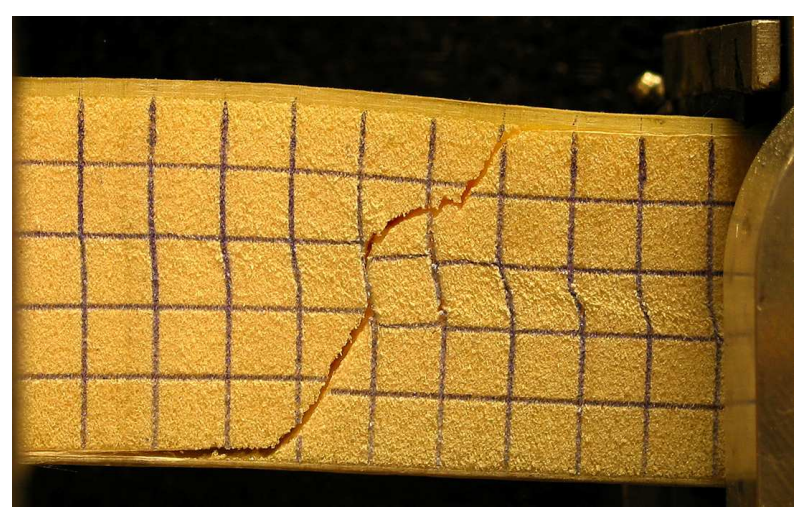

(a)

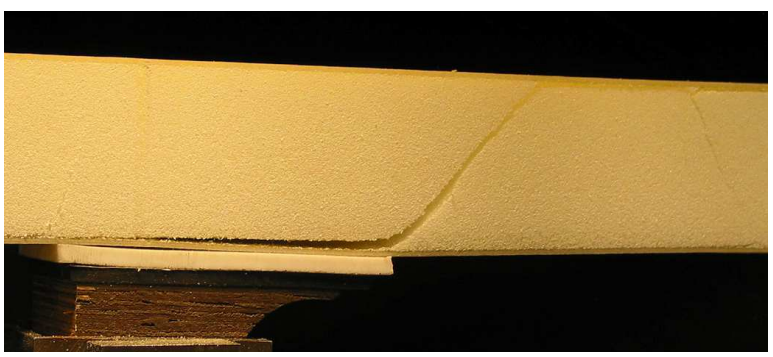

(c)

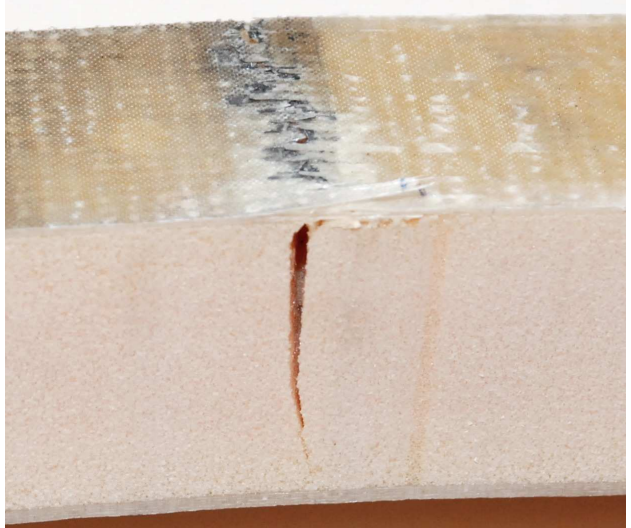

(b)

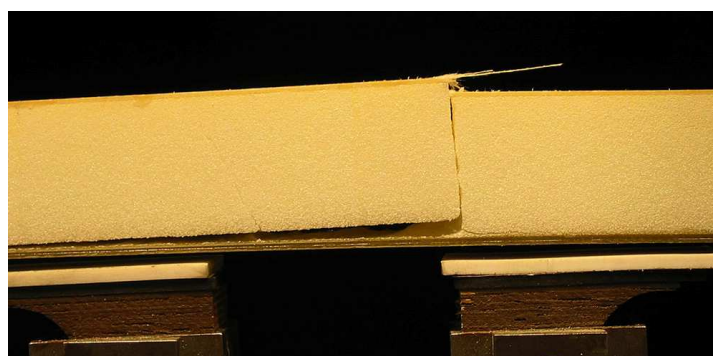

(d)

Figure 6 Photographs of failure modes. (a) $\mathrm{H} 100$ core shear failure, highlighted through painted lines on the core surfaces, (b) H100 beams with tensile face failure, (c) WF51 core shear failure and (d) WF51 beam with laminate failure

The failure modes are shown in Fig.6c and d. The core shear failure is quite obvious in this case. The WF51 is rather brittle and fails abruptly. The face tensile failure also appears abruptly without any prior visual signs of degradation.

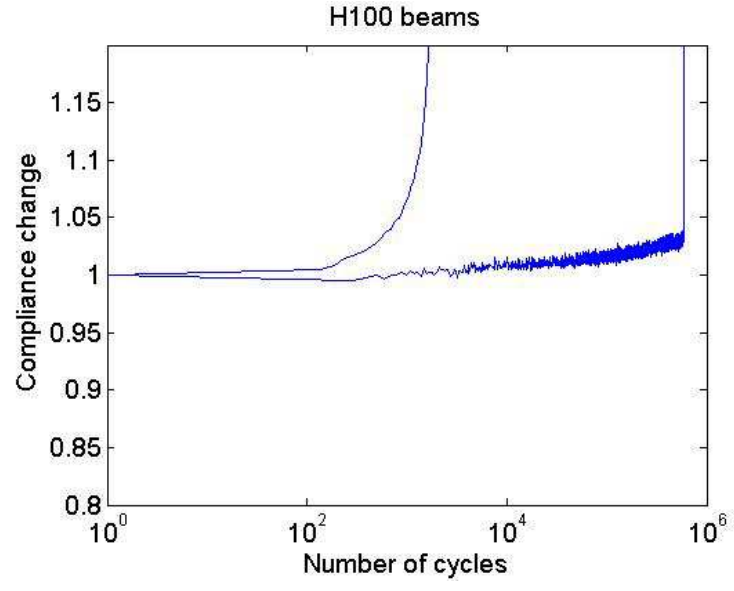

(a)

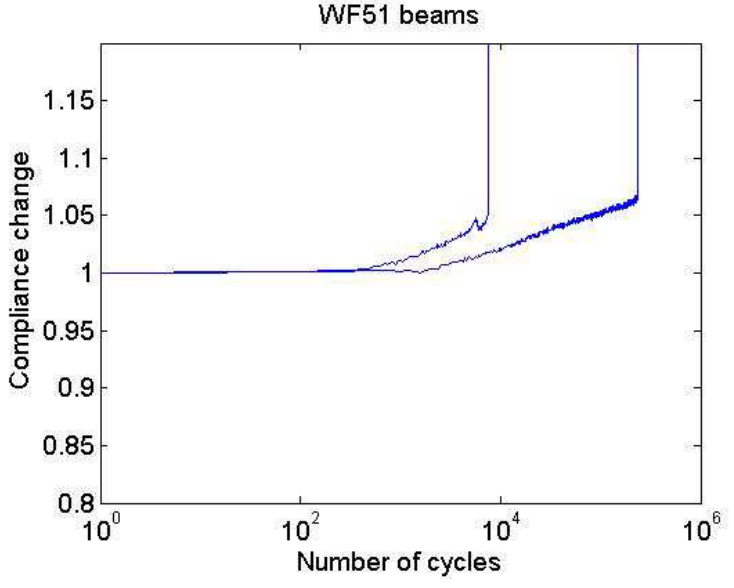

(b)

Figure 7 Testing machine displacement as function of loading cycles for (a) two $\mathrm{H} 100$ beams and (b) two WF51 beams showing the creep behaviour. 
The H100 beams did exhibit some creep deformation during fatigue testing. The compliance change versus number of cycles are shown in Fig.7a for one beam that failed in shear (few cycles to failure) and one that failed by tensile laminated rupture (large number of cycles to failure). The compliance change is calculated as the compliance at load cycle $n$ divided by the compliance at the first load cycle. The compliance is taken as the machine displacement range $\left(\Delta \delta=\delta_{\max }-\delta_{\min }\right)$ divided by the load range $\left(\Delta P=P_{\max }-P_{\min }\right)$ in a load cycle. It is seen that there is some creep deformation during cyclic loading. In order to compare correctly one should know that the cyclic deformation (machine displacement) $\Delta \delta$ was around $13 \mathrm{~mm}$ for the beam failing at 1868 cycles and around $6 \mathrm{~mm}$ for the beam failing at $6 \times 105$ cycles. Thus, the increase in relative displacement from the initial load cycles to the point of failure is quite small, being only fraction of millimetres in the case of high load (1868 cycles to failure) and less than $1 \mathrm{~mm}$ for the low load case (failure at $6 \times 105$ cycles).

The WF51 beams did also exhibit some creep during fatigue testing. The compliance change versus number of cycles is shown in Fig. $7 \mathrm{~b}$ for one beam that failed in shear (few cycles to failure) and one that failed by tensile laminated rupture (large number of cycles to failure). It is seen that there is some creep deformation during cyclic loading. In order to compare correctly one should know that the cyclic deformation (machine displacement) $\Delta \delta$ was around $29 \mathrm{~mm}$ for the beam failing at 7748 cycles and around $23 \mathrm{~mm}$ for the beam failing at $2.37 \times 10^{5}$ cycles. Thus, the increase in relative displacement from the initial load cycles to the point of failure is still small, being only approximately 3 millimetres in both cases.

\section{CONCLUSIONS}

Two types of sandwich beams were designed with respect to fatigue performance of the face sheets and the core. The beams were designed with the aim to promote failure mode shifts as the fatigue loading amplitude was changed. The designed beams were manufactured and tested in fatigue. For high loading amplitudes and few cycles to failure, the beams failed by core shear failure. When the load amplitude was decreased the failure mode shifted to face sheet tensile failure. This shows that although a sandwich structure may be designed for core shear failure, at least to quasi-static loading, the failure mode can still be face sheet failure if 
fatigue loading is applied. The reason for this is that the stress-life life curves for core shear failure and face tensile failure have different slopes.

\section{ACKNOWLEDGEMENTS}

The financial support for this investigation has been provided by The Office of Naval Research (ONR) through programme officer Dr. Yapa D.S. Rajapakse (Grant No. N0001407-1-0344). Evonik and DIAB are acknowledged for supplying the materials. Special thanks to Anders Beckman and Bo Magnusson for help with the manufacturing of the test specimens and the fatigue testing.

\section{REFERENCES}

[1] M. Burman and D. Zenkert., Fatigue of Foam Core Sandwich Beams, Part I: Undamaged Specimens, Int. J. Fatigue 19 (1997) 551-561.

[2] M. Burman and D. Zenkert, Fatigue of Foam Core Sandwich Beams, Part II: Effect of Initial Damages, Int. J. Fatigue 19 (1997) 563-578.

[3] R.A. Shenoi, S.D: Clark and H.G. Allen, Fatigue Behaviour of Polymer Composite Sandwich Beams, J. Comp. Mat. 29 (1995) 2423-2445.

[4] K. Kanny, H. Mahfuz, L.A. Carlsson, T. Thomas and S. Jeelani, Dynamic mechanical analyses and flexural fatigue of PVC foams, Comp. Struct. 58 (2002), 175-183.

[5] K. Kanny and H. Mahfuz, Flexural fatigue characteristics of sandwich structures at different loading frequencies, Comp. Struct. 67 (2005), 403-410

[6] N. Kulkarni, H. Mahfuz, S. Jeelani and L.A. Carlsson, Fatigue crack growth and life prediction of foam core sandwich composites under flexural loading, Comp. Struct. 59 (2003) 499-505.

[7] D. Zenkert, A. Shipsha and M. Burman, Fatigue of Closed Cell Foams, J. Sandwich Struct. \& Mater. 8 (2006) 517-538.

[8] D. Zenkert and M. Burman, Tension, Compression and Shear Fatigue of a Closed Foam, Comp. Sci. Tech. 69 (2008) 785-792. 
[9] M.Z. Shah Kahn and A.P. Mouritz, Fatigue behaviour of stitched GRP laminates, Comp. Sci. Tech. 56 (1996) 695-701.

[10] A.P. Mouritz, Tensile fatigue properties of 3D composites with through-thickness reinforcement, Comp. Sci. Tech., 68 (2008) 2503-2510.

[11] A. Gagel, D. Lange and K. Schulte, On the relation between crack densities, stiffness degradation, and surface temperature distribution of tensile fatigue loaded glass-fibre non-crimp-fabric reinforced epoxy, Compos. Part A 37 (2006) 222-228.

[12] A. Gagel, B. Fiedler and K. Schulte, On modelling the mechanical degradation of fatigue loaded glass-fibre non-crimp fabric reinforced epoxy laminates, Comp. Sci. Tech. 66 (2006) 657-664.

[13] K. Vallons, Z. Mengmeng, S. Lomov and I. Verpoest, Carbon composites based on multi-axial multi-ply stitched preforms - Part 6. Fatigue behaviour at low loads: Stiffness degradation and damage development, Compos. Part A 38 (2007) 1633-1645.

[14] K. Vallons, Z., S. Lomov and I. Verpoest, Fatigue and post-fatigue behaviour of carbon/epoxy non-crimp fabric composites, Compos. Part A 40 (2009) 251-259.

[15] Y. Aono, H. Noguchi, S.-H. Lee, T. Kuroiwa and K. Takita, Fatigue strength of doublebias mat composites composed of stitched unit layers, Int. J. Fatigue 28 (2006) 13751381.

[16] Y. Aono, K. Hirota., S.-H. Lee, T. Kuroiwa and K. Takita, Fatigue damage of GFRP laminates consisting of stitched unit layers, Int. J. Fatigue 30 (2008) 1720-1728.

[17] P. Brøndsted, H. Lilholt and A. Lystrup, Composite Materials for Wind Power Turbine Blades, Annu. Rev. Mater. Res. 35 (2005) 505-538.

[18] R. Nijssen, Fatigue Life Prediction and Strength Degradation of Wind Turbine Rotor Blade Composites, Doctoral Thesis, KC-WMC and Faculty of Aerospace Engineering, Delft University, The Netherlands, 2006, ISBN-10: 90-9021221-3

[19] Divinycell H-grade, Technical Manual, DIAB AB, www.diabgroup.com 
[20] Rohacell WF, Evonik Industries, www.rohacell.com

[21] Devold AMT, Quadriaxial reiforcements, www.amt.no

[22] Zenkert D., An Introduction to Sandwich Construction, EMAS Ltd, Warley, UK, 1995 